\title{
The temperature and moisture distribution of rapeseeds in a fixed bed during microwave-vacuum drying on a semi-technical scale
}

\author{
Anita Kupińska, Antoni Kozioł, Michał Lupinski, Michał Araszkiewicz \\ Wroclaw University of Technology, Faculty of Chemistry, Division of Chemical and Biochemical Processes, \\ ul. Norwida 4/6, 50-373 Wroclaw, e-mail: anita.lupinska@pwr.wroc.pl
}

A research into microwave vacuum drying of rapeseeds in a fixed bed on a semi-technical scale was done. The temperature and moisture distribution for a different value of microwave power and pressure were determined. The economic analysis of the drying processes, description of equipment and measurement methodology were presented, too.

Keywords: microwave-vacuum drying, fixed bed, rapeseeds.

\section{INTRODUCTION}

The rape (Brassica oleifera) is an oil plant, which is particularly important in the temperate climate. The rape is a source of material for many industrial goods. In Europe the rape cultivation area has reached 3 million hectares, which comprises almost 60 percent of the whole area occupied by oil plants ${ }^{\mathbf{1}}$.

The drying process is one of the most important parts of the post-harvest treatment. The quality of this process plays a key part in the account of costs as well as in the quality of rape final products (edible oil, margarine, biofuel, solvent-extracted cake).

The experimental results ${ }^{2}$ show that in the northern region of Poland more than $24 \%$ of drying plants were equipped with the dryers which were produced before the year 1970 and $45 \%$ use the equipment produced after the year 1990. The technical unification of the dryers used, their inspection and the average heating temperature recording stated a problem in the research done. The situation brings about dried rapeseeds' final quality being uncertain in these conditions.

Taking into account that the rate of the rapeseeds drying process is considerably lower than that of corn, different drying conditions should be met. One of the reasons is a greater resistance of a dense packet of rapeseeds bed. Unfortunately, most of fans are compatible with corn specification and a higher static pressure would be generated along with a smaller volumetric flow of air. The process leads to an increase in air temperature, which can be dangerous to the final product quality ${ }^{2}$.

The negative influence of the temperature on the amount of crude fat, raw fibre and its fractions in rapeseeds was observed at temperatures higher than $150^{\circ} \mathrm{C}$. However, drying at temperatures lower than $120^{\circ} \mathrm{C}$ does not have a strong influence on the changes of the amount of basic components of rapeseeds ${ }^{3}$.

\section{MICROWAVE DRYING}

The microwave drying process is characterized by high power efficiency, sterility and control comfort as well as automation ${ }^{4}$.

The maximum temperature at which the material is damaged or sterilised is a frequent limitation on biological materials drying. The problem can be solved by using the microwave energy and reduced pressure. The temperature can be controlled in a simple and effective way through the regulation of pressure and power of the electromagnetic field. This so- lution allows economising on time and material in the process.

Most of microwave drying experiments that have been published were carried out on a laboratory scale ${ }^{\mathbf{5 - 1 0}}$. The semi-technical scale is more useful in precise description of process parameters that are necessary for the design of the practical process.

\section{THE OBJECTIVES}

The main objective of the work was to determine the temperature and moisture distribution profiles of rapeseeds in a fixed bed for a different value of microwave power and pressure. The schedules allow one to define the range of effective microwave field-work and are helpful in explaining which parts of the bed are heating-up most. The knowledge can be useful for the optimization of the drying equipment to keep bed temperature uniform. The drying time for the used microwave power was determined, too. The next objective was the economic analysis of the microwave vacuum process.

\section{THE EXPERIMENTAL SETUP}

The experiments were conducted using the research equipment shown in Figure 1. The experimental setup consisted of a steel tank (1), a perforated insert (2) with the rapeseeds bed (3), a microwave antenna (4), a microwave generator controller (5), a tank with a cap and pumps and thermohygrometer outputs (6), vacuum pumps (7), a manometer (8), a thermocouple system with data logger (9) and a compensatory tank with a condenser (10).

The experiments were conducted in a static seed-bed with an initial dry mass of $146 \mathrm{~kg}$. At the beginning the absolute moisture in the bed was approximately $30 \%$. The initial tem-

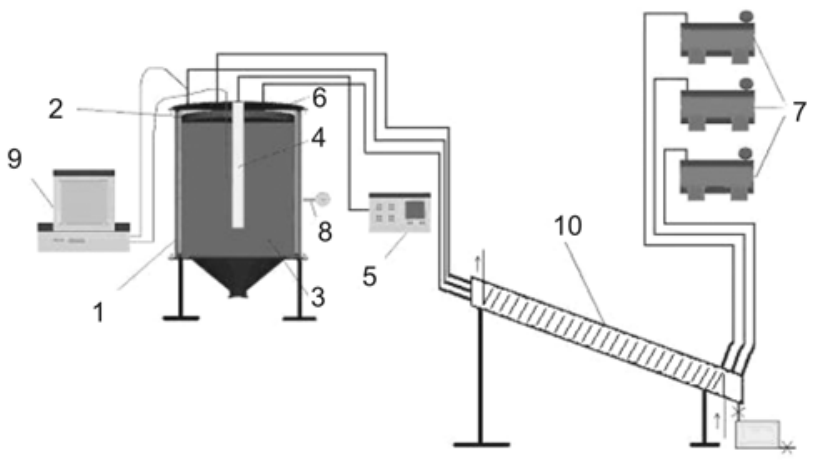

Figure 1. A semi-technical scale research equipment 
perature of the bed was $17^{\circ} \mathrm{C}$. The rapeseeds bed was heated up with the following microwave power and pressure values: $520 \mathrm{~W} 0,04 \mathrm{MPa}, 860 \mathrm{~W}$ 0,04 MPa, $520 \mathrm{~W}$ 0,08 MPa. The bed was dried in a half-time mode - the microwaves were turned on for 2 minutes and then turned off for the next 2 minutes. The temperature distribution was determined with a special thermocouple that was 1 meter long. After each 20 minutes of microwave heating-up the thermocouple was placed in the bed (in 5 different distances and 5 different depths from the microwave antenna). The process lasted until the warmest place of the bed reached the temperature of $60 \div 70^{\circ} \mathrm{C}$. After this time, the microwave heating-up was stopped and the bed cooled down for 18 hours - during this time warmer the parts of the bed transferred the heat to its colder parts. After 18 hours, the bed was heated once again using microwaves until

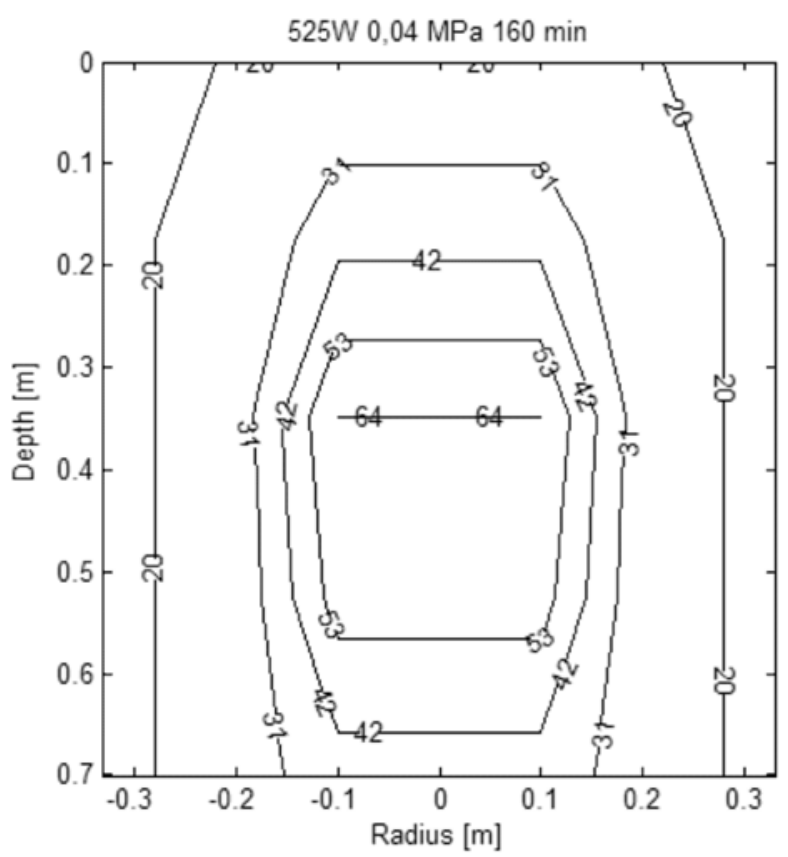

it reached the temperature of $60 \div 70^{\circ} \mathrm{C}$. The process lasted for 4 days. A day after the end of microwave heating-up, samples of rapeseeds were taken from different parts of the bed and a final moisture distribution was determined by weight.

\section{THE RESULTS}

The temperature distribution of rapeseeds in the fixed bed on the first day of microwave drying at a moment of reaching the temperature of $60 \div 70^{\circ} \mathrm{C}$ and initial temperatures after 18-hour break are shown in Figures 2, 4 and 6. Figures 3, 5 and 7 display the temperature distribution on the fourth day (after the bed reaching the temperature of $60 \div 70^{\circ} \mathrm{C}$ ) and the final temperature distribution after 18-hour break.

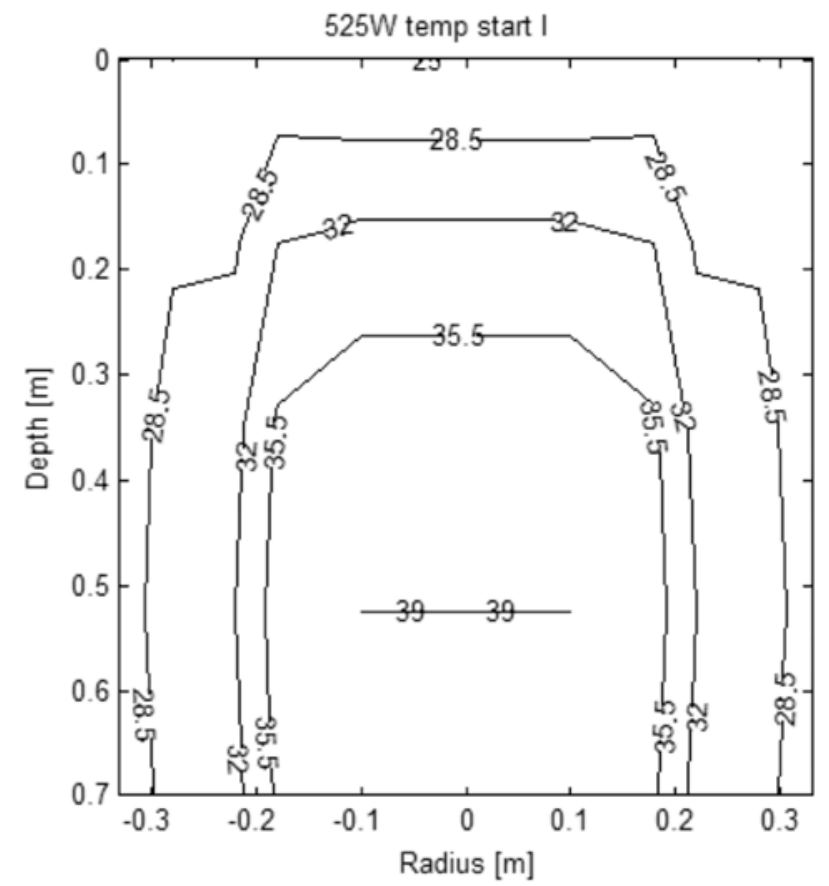

Figure 2. The temperature distribution of rapeseeds in a fixed bed after 160 minutes (first day) of microwave heating-up and the initial temperature distribution after the 18-hour break (microwave power $525 \mathrm{~W}$, pressure $0,04 \mathrm{MPa}$ )
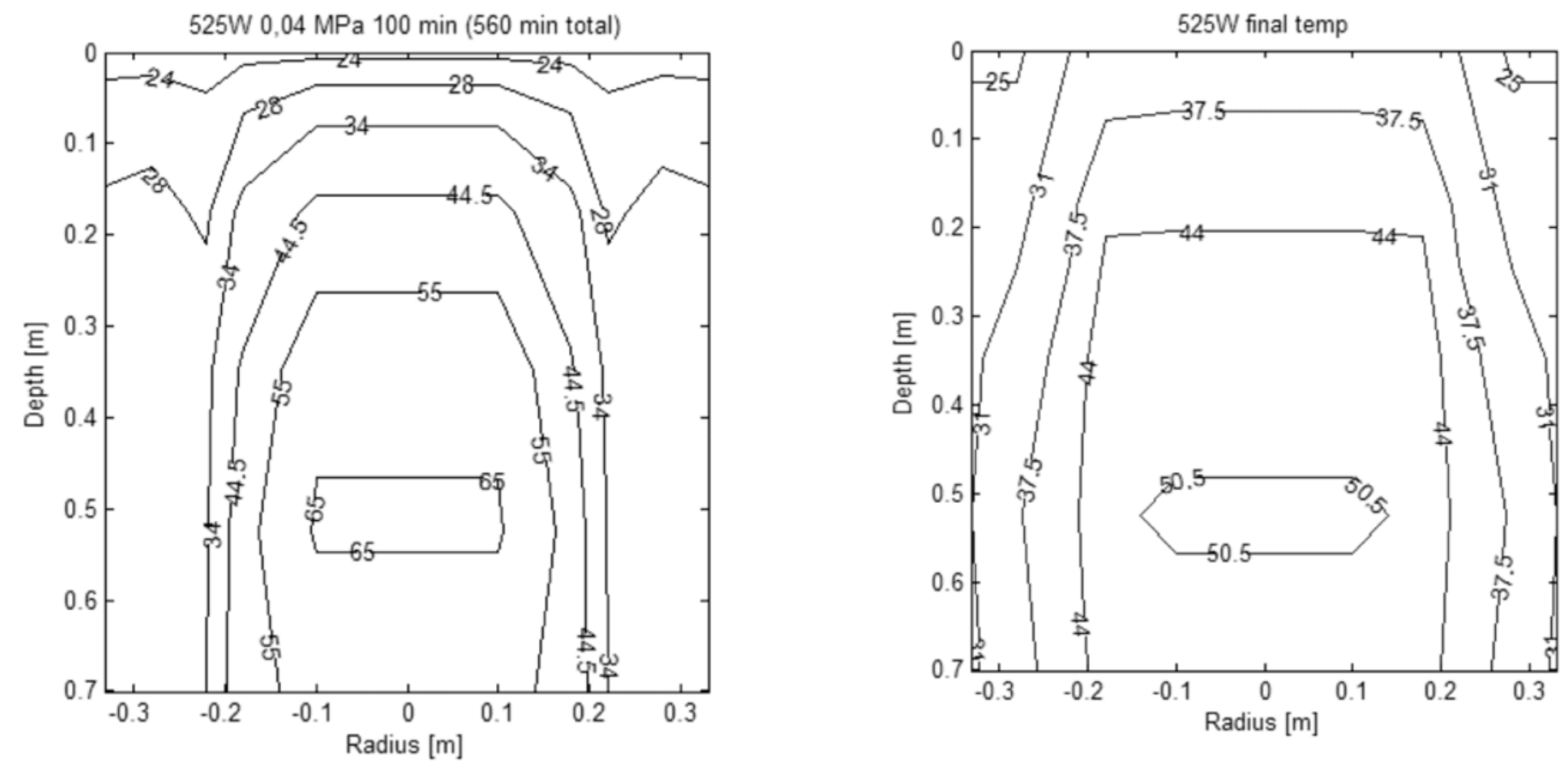

Figure 3. The temperature distribution after 560 minutes of total microwave heating-up (fourth day) and the final temperature distribution after the 18-hour break (microwave power $525 \mathrm{~W}$, pressure 0,04 MPa) 

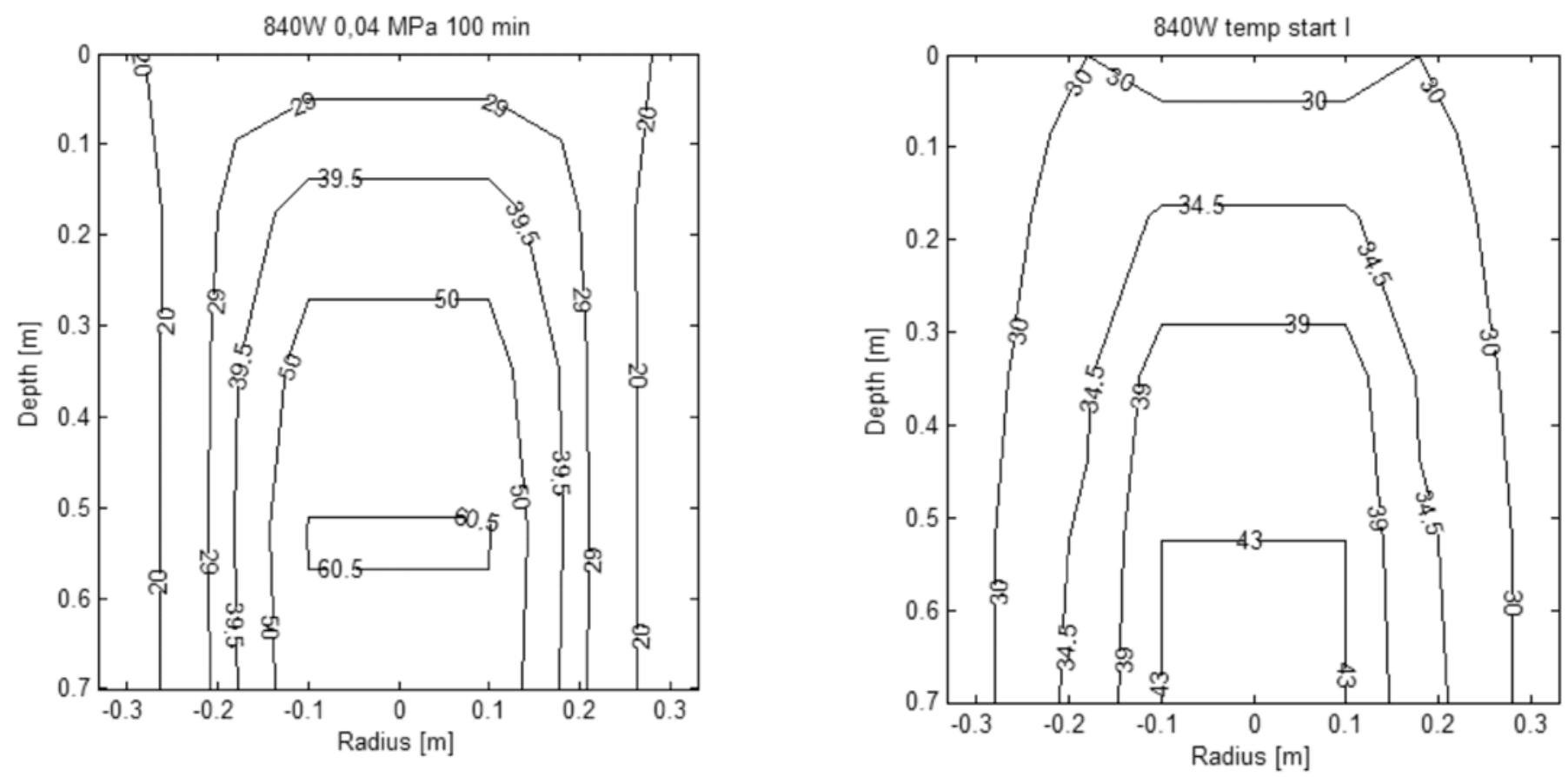

Figure 4. The temperature distribution of rapeseeds in a fixed bed after 100 minutes (first day) of microwave heating and the initial temperature distribution after the 18 -hour break (microwave power $840 \mathrm{~W}$, pressure 0,04 MPa)
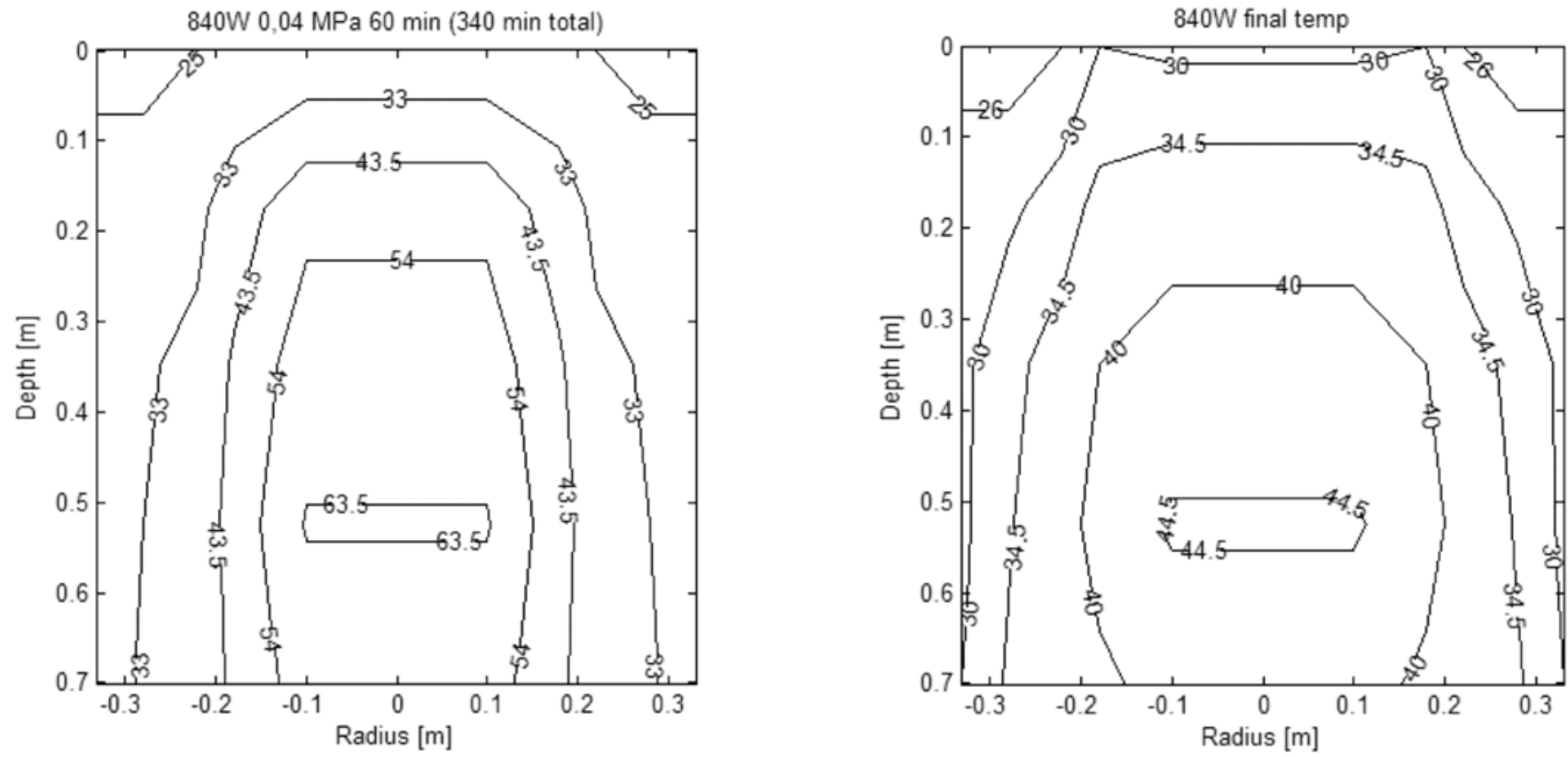

Figure 5. The temperature distribution atter 340 minutes of total microwave heatıng-up (tourth day) and the tinal temperature distribution after the 18 -hour break (microwave power $840 \mathrm{~W}$, pressure $0,04 \mathrm{MPa}$ )

The previous figures show that the highest temperatures were noted in the centre of the bed, while the lowest temperatures - on the bed's surface and edges. The temperature distribution has a spherical course - the centre is placed in the final part of the microwave antenna.

After several days of the drying process, the highest heat generation was noted in the centre of the bed - it stems from the fact that oil, which makes up the content of rapeseeds, was heated-up in the process, too.

The pressure was not observed to influence the temperature distribution in the bed. The rate of bed heating-up was clearly bound up with the rate of the used microwave power. The microwave heating-up was effective within 0,20 meter from the microwave antenna and further parts of the bed were heated-up by thermal conduction. In order to obtain an equal heating-up of the bed several microwave antennas should be set in the distance of 0,4 meter from each other.

Figures 8 and 9 display the final absolute moisture distribution of the bed that was determined by weight. The initial absolute moisture value for particular processes was: 30,8\% for $525 \mathrm{~W} 0,04 \mathrm{MPa}, 32 \%$ for $840 \mathrm{~W} 0,04 \mathrm{MPa}$ and $27 \%$ for $525 \mathrm{~W} 0,08 \mathrm{MPa}$.

The final absolute moisture distribution show that the centre of the bed was dried most. The rapeseeds bed heated up with the microwave power of $525 \mathrm{~W}$ and the pressure of 0,04 MPa was dried most equally. The average value of the final absolute moisture of the bed for these particular processes was: 3,2 \% (525 W 0,04 MPa), 4,1 \%(840W 0,04 MPa), 4,9\% (525W 0,08 MPa). 

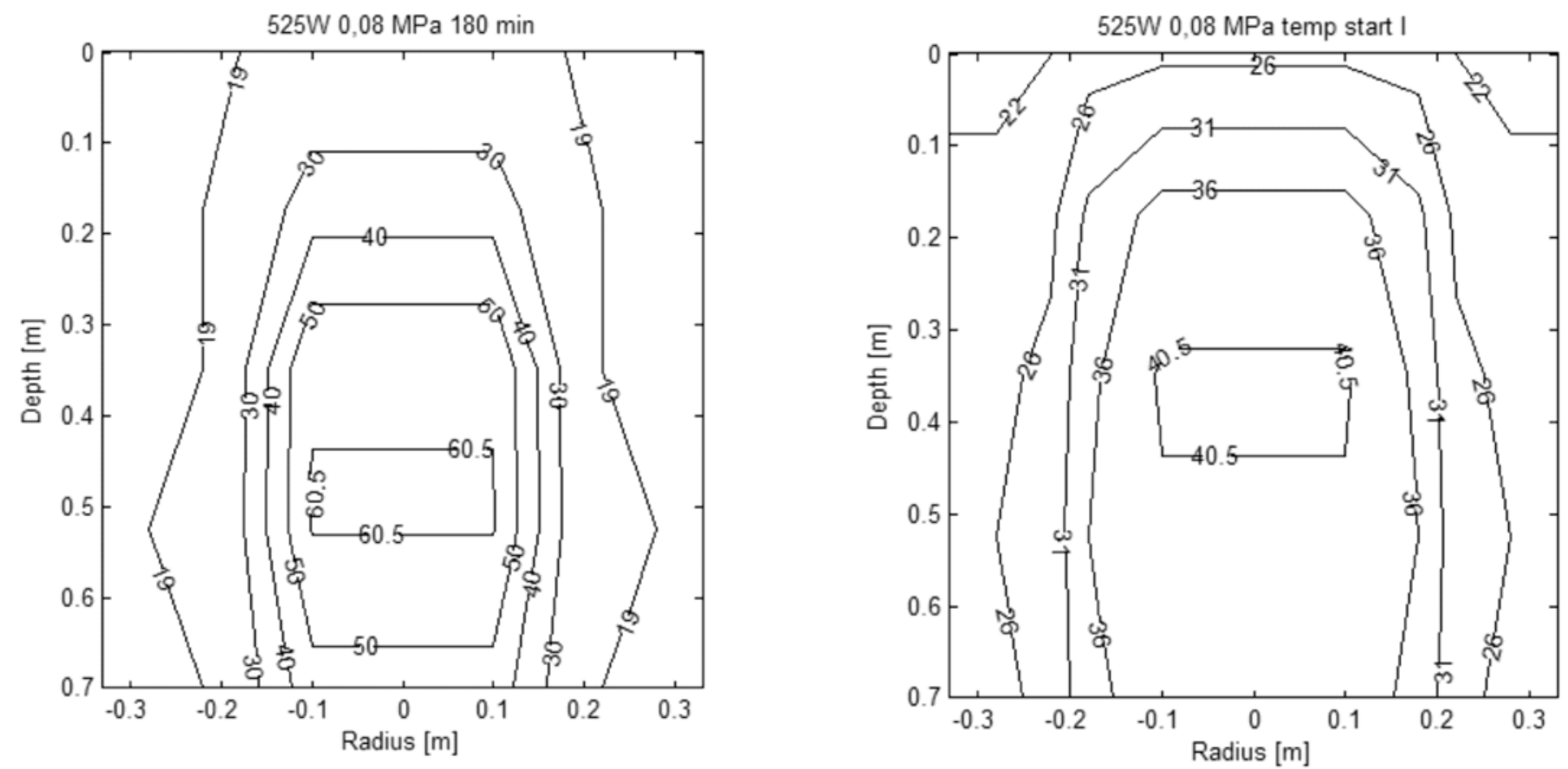

Figure 6. The temperature distributions of rapeseeds in a fixed bed after 180 minutes (first day) of microwave heating-up and the initial temperature distribution after the 18-hour break (microwave power $525 \mathrm{~W}$, pressure $0,08 \mathrm{MPa}$ )
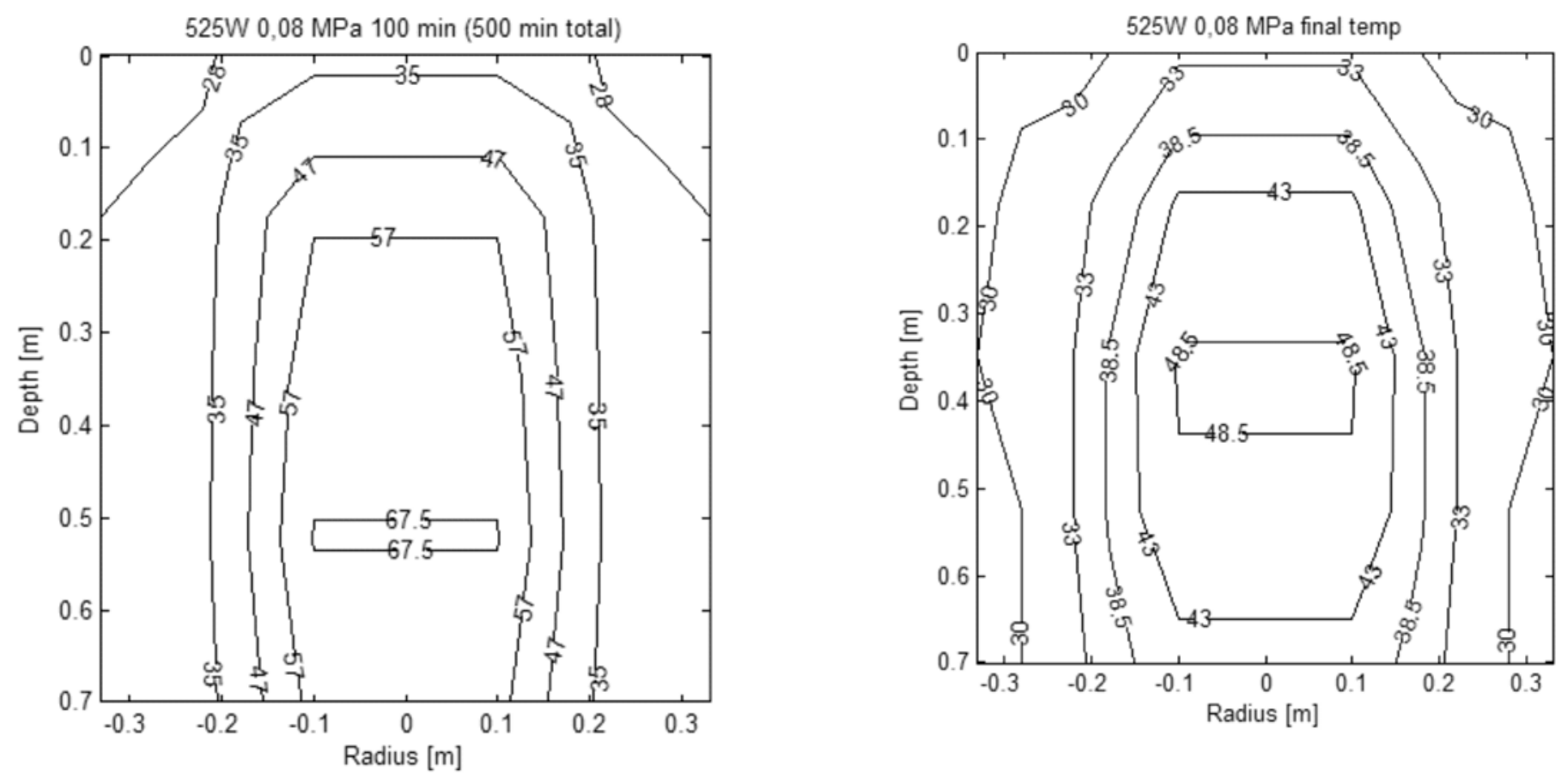

Figure 7. The temperature distribution after 500 minutes of total microwave heating-up (fourth day) and the final temperature distribution after the18-hour break (microwave power $525 \mathrm{~W}$, pressure $0,08 \mathrm{MPa}$ )

Figure 10 presents energy expenditure of the microwave generator and the vacuum pump. The power of the pump was $550 \mathrm{~W}$ and the electrical efficiency of the microwave generator was $65 \%$. For every 10 minutes of microwave drying in a half-time mode, the microwave generator worked for 6 minutes.

Energy consumption of the microwave generator is similar in each of the three processes (nearly equal for the first and second process, whereas a little lower for the third one). The largest differences in energy consumption are visible for the pump. The highest energy consumption occurred in the first

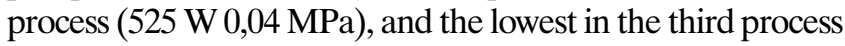
(525 W 0,08 MPa). The differences between these processes stemmed from different process pressure used - at a pressure of 0,04 MPa the pump had to work longer. For the processes conducted at $525 \mathrm{~W}$ and $840 \mathrm{~W}$ and the same pressure of 0,04 $\mathrm{MPa}$, the working time of the pump was approximately $65 \%$ longer for $525 \mathrm{~W}$ process - the pump worked simultaneously with a microwave generator (during the 18-hour breaks the pump didn't work).

The cost of the reduction of the absolute moisture of the bed by $1 \%$ for each process was correspondingly: $257 \mathrm{Wh}(525 \mathrm{~W}$ 0,04 MPa), $214 \mathrm{Wh}$ ((840 W 0,04 MPa), $224 \mathrm{Wh}$ (525 W $0,08 \mathrm{MPa})$. The most economical process is the one when microwave power was at $840 \mathrm{~W}$ and pressure at 0,04 MPa. 

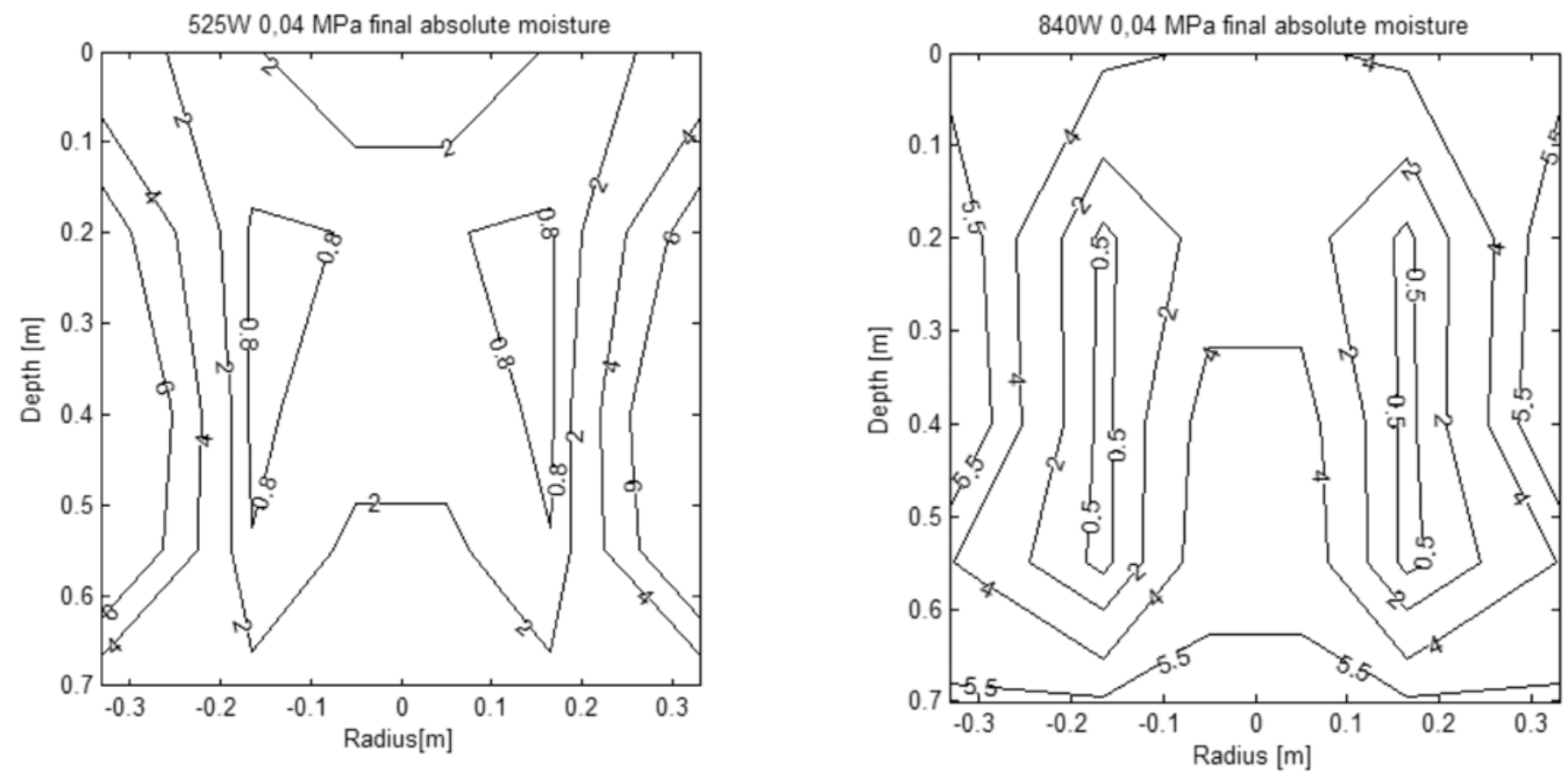

Figure 8. The final absolute moisture distribution of rapeseeds in a fixed bed for the microwave power of $525 \mathrm{~W}$ and $840 \mathrm{~W}$ and pressure $0,04 \mathrm{MPa}$

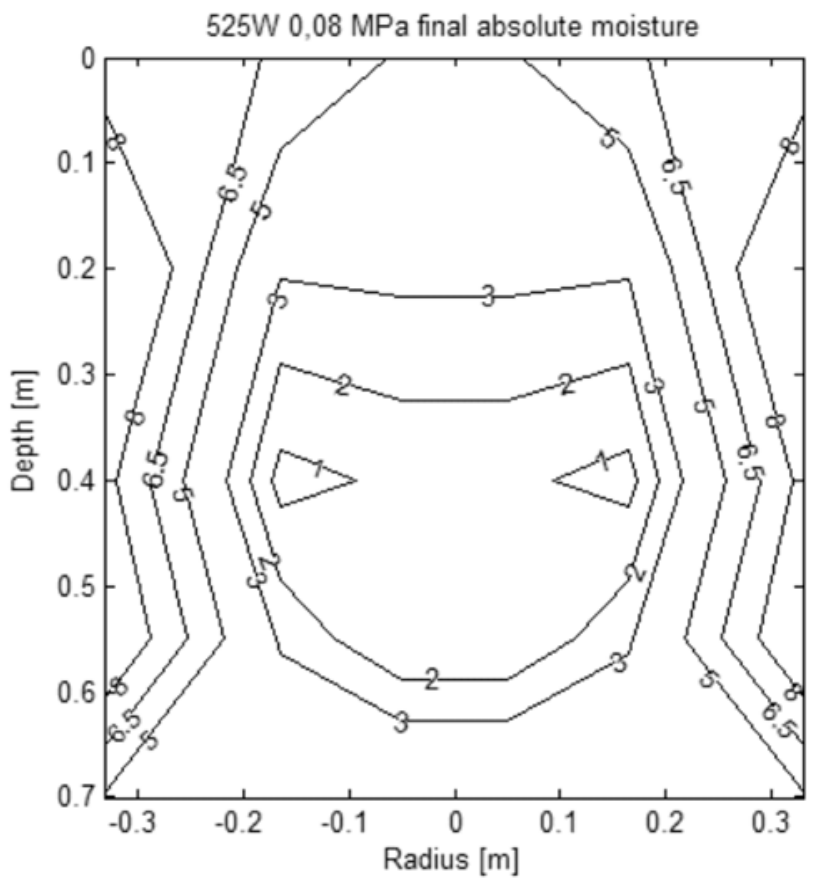

Figure 9. The final absolute moisture distribution of rapeseeds in a fixed bed for the microwave power $525 \mathrm{~W}$ and pressure $0,08 \mathrm{MPa}$

\section{SUMMARY}

- When a microwave antenna was placed in a geometric centre of vessel, the fixed bed was heated mostly near the antenna and temperature distribution had spherical shape,

- The depth of microwave penetration in rapeseeds in a fixed bed was about $20 \mathrm{~cm}$ and above this value the bed was heated up by thermal conduction,

- For a uniform heating-up of the bed several microwave antennas should be placed within the distance of 0,4 meters between each of them. However, when a single antenna is used, more time should be given to equalize the temperature in the vessel,

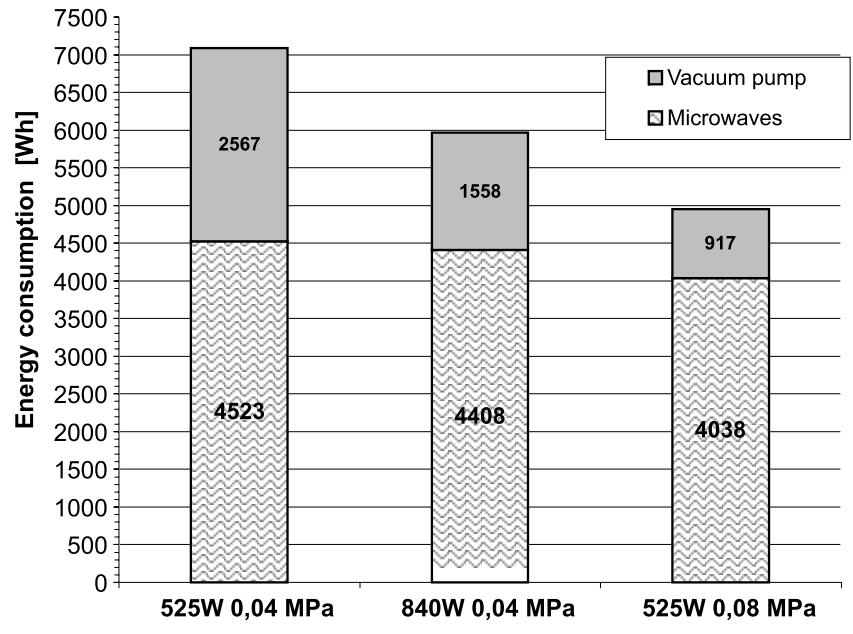

Figure 10. Energy consumption for each process

- Heat generation in rapeseeds in a fixed bed took place even after a few days of experiment, when water amount was very small. It was obvious that rape oil generates heat in the microwave field,

- The pressure influence on temperature distribution is minimal. However, pressure clearly influences moisture distribution,

- The most expensive process was at $525 \mathrm{~W}$ and 0,04 $\mathrm{MPa}$ and the cheapest at $840 \mathrm{~W}$ and 0,04 MPa parameters,

- The most effective process was at $525 \mathrm{~W}$ and 0,04 $\mathrm{MPa}$,

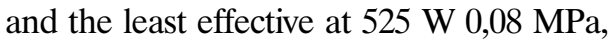

- The semi-technical scale research work allowed defining the range of microwave heating-up. The temperature distribution results can be used for the optimization of microwave heating systems in order to obtain the uniformity in the heated up bed,

- The economic analysis in connection with moisture distribution allows to choose the best process parameters in order to achieve the optimal economic and quality conditions 


\section{ACKNOWLEDGMENT}

This work was carried out as a part of research projects No 3 T09C02529 sponsored by the Polish State Committee for Scientific Research.

\section{LITERATURE CITED}

1. Bartkowiak-Broda, I. (2004). Directions of the winter rape farming. Rapeseeds, $17-21$.

2. Tys, J., Sobczuk, H. \& Rybacki, R. (2002). Influence of drying temperature on mechanical conditions of rapeseeds. Oil Plants (2), 417 - 426.

3. Krasucki, W., Tys, J., Szafran, K., Rybacki, R. \& Orlicki, L. (2002). Influence of various drying temperatures on chemical composition of rapeseeds. Oil Plants (2), 427 - 438.

4. Araszkiewicz, M., Koziol, A., Lupinska, A. \& Lupinski, M. (2006). Temperature distribution In a single sphere dried with microwaves and hot air. Drying Technology (24), 1381 1386.

5. Pere, C. \& Rodier, E. (2002). Microwave vacuum drying of porous media: experimental study and qualitative considerations of internal transfers. Chemical Engineering and Processing (41), 427 - 436.

6. Sumnu, G., Turabi, E. \& Oztop, M. (2005). Drying of carrots in microwave and halogen lamp-microwave combination ovens. LWT (38), 549 - 553.

7. Maskan, M. (2000). Microwave/air and microwave finish drying of banana. Journal of Food Engineering (44), 71 - 78.

8. Maskan, M. (2001). Drying, shrinkage and rehydration characteristics of kiwifruits during hot air and microwave drying. Journal of Food Engineering (48), 177 - 182.

9. Itaya, Y., Uchiyama, S. \& Mori, S. (2007). Internal heating effect and enhancement of drying of ceramics by microwave heating with dynamic control. Transport in Porous Media (66), 29 - 42.

10. Kowalski, S. J., Rajewska, K. \& Rybicki, A. (2004). Mechanical Effects in Saturated Capillary-Porous Materials during Convective and Microwave Drying. Drying Technology (22), $2291-2308$. 